\title{
Research on the Practice and Reform of the Ordinary University Sports Curriculum with Internet Aided Instruction Mode
}

\author{
Hong Zhou \\ Wuchang ShouYi University, Road Nanli 22\#, \\ Wuhan, Hubei, 430064 China
}

\begin{abstract}
In this paper, we conduct research on the practice and the reform of the ordinary university sports curriculum with the Internet aided instruction mode. With the rapid popularization of the Internet application, not only traditional teaching ideas, teaching means, teaching content, teaching process and teaching organization changes, and will cause the fundamental changes of teaching mode and education system. The interaction of networked multimedia software, the simulation education system, information sharing system will play a role of main force in the teaching. Campus network has been widely established in our country nowadays, how to make the teachers and students to adapt to the fast-changing digital living environment as soon as possible, understand and access to sports education through the Internet information resources, and the information obtained is the accurate analysis, evaluation and reasonable use, service for teaching and the scientific research, education workers in colleges and universities is facing a major issue.
\end{abstract}

Keywords- Practice and Reform, University Sports, Internet, Aided Instruction, Curriculum.

\section{Introduction}

Physical education is an important part of the higher education that is to cultivate moral, intellectual, physical, all-round development talent essential important content. Sports in colleges and universities to carry out the rich and colorful cultural activities, not only can enrich the students' amateur cultural life, stimulates the student to study the physical knowledge, to participate in fitness exercise, improve the enthusiasm of physical quality can deepen the education reform in colleges and universities, to optimize the education environment for building up healthy culture of colleges and universities.

The reform of the college sports curriculum system structure and development direction lies in the effective use of primary innovative elements, the university sports curriculum structure on thought transformation, characteristic of sports development in the important position in university, highlight the "superiority" of physical education curriculum system structure. Since China's reform and opening up, along with the continuous development of colleges and universities around the country, all kinds of college sports professional colleges and universities not only training a large number of the sports talents, as well as transport a large number of outstanding sports teachers' colleges and universities. Overall, sport teacher in colleges and universities still has been constantly enriched and development. But compared with the rapid development of colleges and universities in recent years that objectively speaking, the current college sports teachers cannot adapt embodied in the following respects. (1) For a long time, our teacher always referred to as cadre management, recruitment and the administrative appointment is a plan and deployment of employment management system as many aspects are not really into competition and the incentive mechanism. (2) Title structure changed a lot in recent years, physical education 
teachers, associate professor of the proportion is growing rapidly, but really play a leading role in the academic is professor of request, and also accounted for a large proportion of the young assistant, including title structure proportion is not enough. (3) With the establishment of the socialist market economy, people's ideological concept, the value orientation, is witnessing profound changes. In the face of the new changes, teachers feel the pressure, in enhancing the competitive at the same time which also produced some negative effects [1-4].

The current research on culture as the leading factor, to borrow from cultural structuralism in the campus of all elements related to sports, to form based on sports material culture, system culture for characterization of sports and sports spiritual culture as the core of mutual promotion and common development of colleges and universities sports culture system. But in the process of research, found that the colleges and universities sports culture research as well as the study of culture has tendency to "visualization", cannot be conducted in-depth and comprehensive research, existing in colleges and the universities sports culture research concrete problems to be solved. In realizing the function of its own at the same time, the campus every structural elements within the scope of influence of campus sports culture, reflects the attributes of the campus sports culture is the campus organic whole benign operation of the indispensable important component.

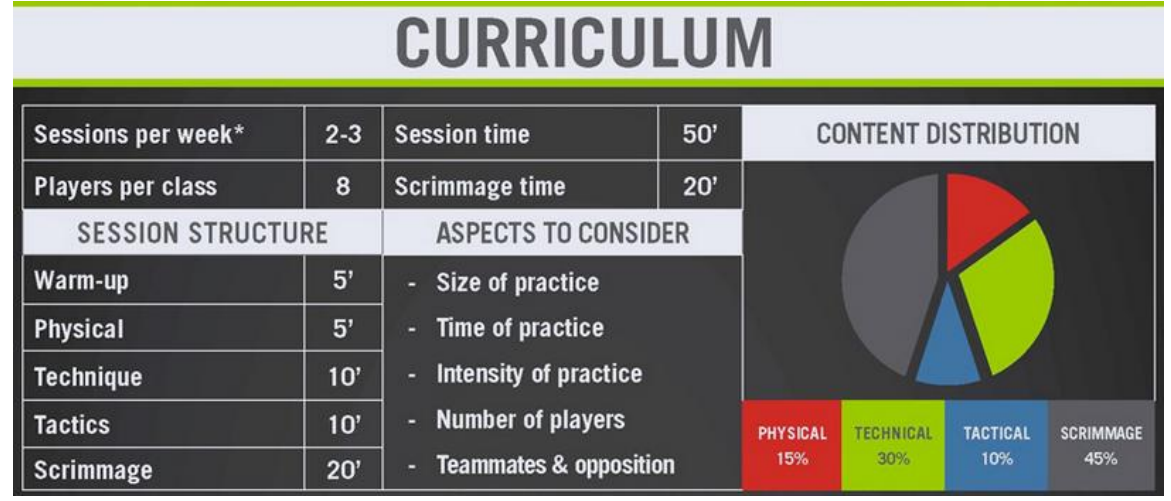

Figure 1. The Sample Ordinary University Sports Curriculum

In this paper, we conduct research on the practice and the reform of the ordinary university sports curriculum with the Internet aided instruction mode. Sport teaching technology refers to the physical education is given priority to with the sports technology teaching and learning, training of the teaching process, this is the main characteristic of physical education curriculum teaching in our country. But for physical education teaching is a kind of sports and cultural education course, it must also carry the value and function of teaching. Sports teaching is a way of education implementation, as also should with education as a starting point in the target task to implement and can truly reflect the education value and the function of physical education teaching.

\section{Our Proposed Methodology}

The Concepts of the Education Reform. College teachers' teaching object is in the information age with the latest knowledge of the college students, they and their own knowledge structure of teachers' teaching ability put forward higher requirements, so the modern university teachers' self-development consciousness is very strong, in the pursuit of better new knowledge, reflection on teaching practice, to explore the process of formation, the high skill development and personal teaching efficacy. 
College students as a relatively mature stage, the physical and mental development should be able to arrange their own university study and life, but in reality, college students' negative reports emerge in endlessly that become workers and researchers concern. Education is foundation of development of science and technology and training talents, the pilot in the modernization drive, the overall effect, so we must put education on the strategic position of priority development as development of education undertakings for national strength, to cope with the international competition and the comprehensive construction well-off society that has the very vital significance [5].

Mechanism can be explained by the system and the principle here two meanings, which reflects the institutional guarantee for the educational reform work institutions, mechanism lies in whether in the systemic science educational reform work. (1) Educational reform work belongs to primary system engineering, which mainly includes the revision of the curriculum standards and the talent training scheme, the reconstruction of the teaching style, teaching the teachers troop construction, the content of the cooperation in the running schools between colleges, etc. This means that, from a micro part teaching mode innovation is incorrect we must follow the laws of the science to develop. (2) Teaching reform of the implementation of main body is mainly composed of front-line teachers, and combined with various functional departments of personnel. Can be seen from this point, the extent to which the innovation of the educational reform pattern directly depends on a line of teachers' understanding of the educational reform, and its role in the educational reform work. When resistance still exists, the educational reform quality inevitably faces is weakened. (3) It is necessary to develop for a long time, colleges and universities educational reform work shows a tendency of one-way feedback is always to appear with the attitude of education department of wishful thinking.
Therefore, in the creation of the realistic foundation also should attach importance to students' status [6-7].

In the management system reform at the same time, the direction of the reform of the internal mechanism of colleges and the universities incentive project is the so-called incentive is a systematic engineering method, through a comprehensive range of incentives, so as to maximize development of the teachers and student staff enthusiasm and creativity of the integrated management method.

The University Sports Education. Sports teaching environment to the ordinary university sports teaching activities of each link, and the students' cognitive development, with learning motivation, learning effects, physical and mental health, ideological quality and aesthetic concept has important influence in many aspects. Therefore, compared with the other subjects teaching, the sports teaching environment on the impact of the ordinary university sports teaching is more direct, more dominant. To make these effects to promote student health and improve the teaching efficiency of development, we must be timely know and grasp the current core situation of the ordinary university sports teaching environment and dynamic development and changes.

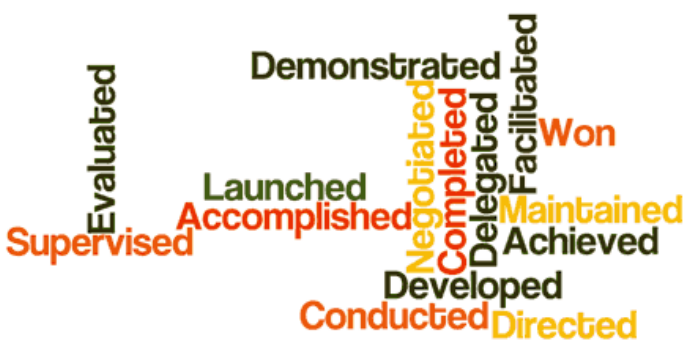

Figure 2. The Keywords of the Ordinary University Sports Education

Notice to deepen university sports curriculum structure reform process, will exist in the traditional curriculum structure and full of the advantages of effective mining, the innovation and development ideas combined with the traditional curriculum system advantage, that 
play traditional colleges and universities sports curriculum has the great development potential. "Development" is an important concept, promote new form for the university sports curriculum structure reform, development is still the fundamental principle, also is our country university sports curriculum structure reform to explore the spirit of the pursuit while it is the necessary factor to realize "innovation", the university sports curriculum structure to realize the objective of "sustainable development" the important thoughts.

Theoretical teaching is the foundation of university physical education curriculum development, is also a key part of the concrete implementation. The reform of the college sports curriculum system structure relies on the innovation of traditional sports in the colleges and universities to carry out the forms, the perfect combination of theory teaching and practice process to develop university students' sports knowledge, to realize the improvement of sports cognition degree. Theory knowledge transfer process is the necessary link of university sports overall development, for college students, the theory of knowledge transfer process is the initial process of sports knowledge and the inner thoughts of a positive role in promoting. Colleges and universities sports culture and traditional means for sport in colleges and universities to develop and popular with universality, repeated and relative stability of a kind of collective behavior habits, it is an organic part of school spirit. Good school sports culture and traditional subtle influence on students, students to form correct sports attitudes, interests, hobbies, to form a good habit of the physical exercise and improve the students' sports culture quality [8].

The Internet Aided Instruction Mode. Network teaching mode mainly based on constructivism learning theory, students as the main body of learning is actively constructing of knowledge. As a new teaching mode, network teaching has openness, flexibility, autonomy, interactivity, and personalized features which could be summarized as the follows. (1) Network teaching resources, as a carrier for the stored in electronic network and transmission medium of digital information resources, to let the students get rid of the basic limitations for the center with books, expand the content of knowledge information, fully mobilize students' multiple senses, provide a good learning situation for students, while realizing their aptitude and students' personalized learning. (2) Network teaching of teaching mode is based on the syllabus and the requirements, and designs the multimedia teaching software, network courseware design and development as network course, posted on school teaching resources center server, student access to the server through a computer network, registration and select courses to learn. (3) Network teaching to students as the center, no geographic and time and space constraints. It is determined by the students' time and place according to the actual situation of individual choice high quality of network education resources for learning can choose the most suitable for their own learning teacher and also can choose their own needs of multimedia teaching courseware.

Multimedia network teaching pattern is on the computer in the teaching activity process under the network environment the stability of the structure form that is a new type interactive teaching mode. Traditional teaching is given priority to with teachers, centering on the textbook and your class, the students passively accept knowledge, and multimedia network teaching changed the teacher's center position, take the student as the main body in the teaching, has broken the time space limitations can students autonomous learning, and greatly increase the flexibility of learning and pertinence. In the figure three, we show the characteristics of the Internet aided instruction mode. 


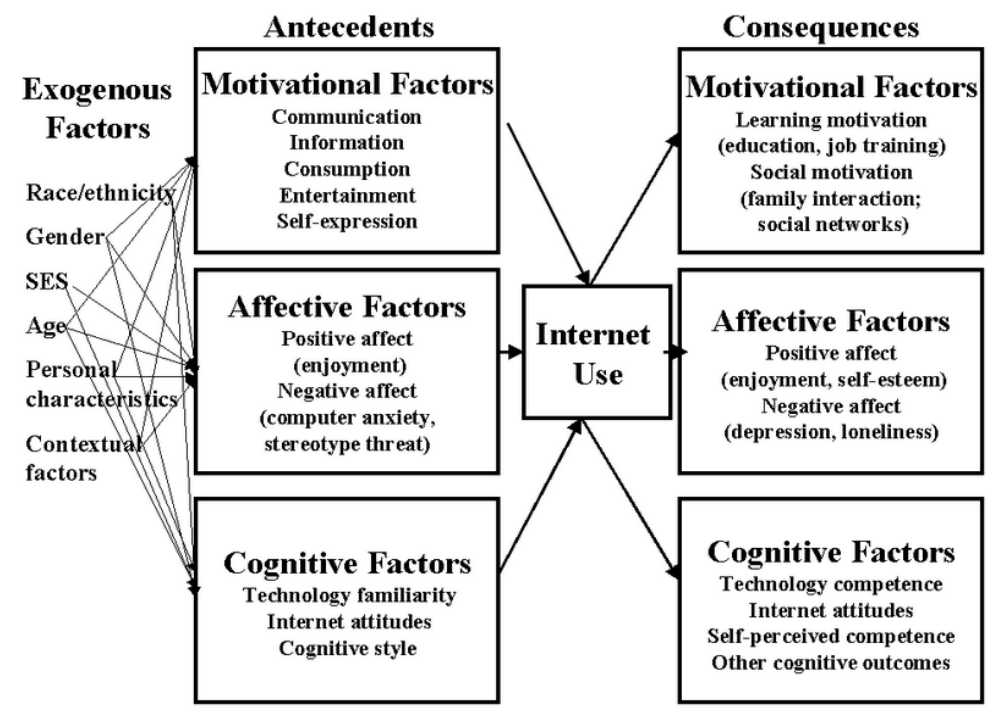

Figure 3. The Characteristics of the Internet Aided Instruction Mode

The Sports Curriculum with Internet. Sports information is based on information technology as the clue, sports application module for the object, with an open view, study application of information technology in sports situation, actively guide the transfer application in the field of the information technology to sports, to better promote the development of sports in the information age. School sports work the informationization in the universities sports teaching the application of the specific performance, sports management, sports training, sports economics, sports, etc. in the application of information technology which can be organized as the following components.

- Modern remote education management system of sports. Used to classify the sports network teaching resources management, building into a unified sports teaching repository, for all kinds of sports network courseware making and teaching provides information support.

- Network courseware development is the new model of preparing through network courseware design tool, and with the support of corresponding database, multimedia courseware can be completed quickly generate, portable, general interactive requirements. Including the network courseware development tools, multimedia network course resources the network courseware development template library.

- Network teaching system is to provide remote teaching service system software will network curriculum and school of distance education service to carry on the organic integration.

- Network course is through the network performance of a certain subject teaching content and implementation of the sum of teaching activities, it includes two parts: according to the certain teaching target, teaching strategy to organize the teaching content and basic support network teaching environment and corresponding resources.

\section{Conclusion}

In this paper, we conduct research on the practice and the reform of the ordinary university sports curriculum with the Internet aided instruction mode. The ordinary university sports teaching process information widespread poor information consciousness, information ability and the information resource poor quantitative information consciousness, information ability, 
information resources quantitative needs to be strengthened, and so should pay attention to the policy guide, set up modern information awareness, strengthening teachers' skill training, improve the level of information quality and technology, application of information technology in teaching and scientific research, encourage teachers implement teaching system innovation, technology innovation and management innovation to improve the traditional teaching contents, adjust the structure of the teaching, strengthen teaching effect an show the sports teachers' information literacy. Our research proposes the corresponding suggestions for the topics that hold special meaning.

\section{References}

[1] HU, Qi, and Nai-jun CHANG. "Study on the Indicator System of Curriculum Teaching Assessment in Sports Humanism Social Science-Taking the Sport College of Shanxi Normal University for Example." Sports Research and Education 3 (2013): 015.

[2] GE, Xiao-Jun, and Ying CHENG. "Cultural Reflections on the Development of School-based Traditional Ethnic Sports Curriculum in Middle and Primary School in Ethnic Regions." Journal of Chuxiong Normal University 3 (2013): 017.

[3] Heidbuchel, Hein, et al. "Position paper: proposal for a core curriculum for a
European Sports Cardiology qualification." European journal of preventive cardiology 20.5 (2013): 889-903.

[4] Madey, Jason, et al. "A Model for Developing and Incorporating a Sports Neurology Program in Neurology Residency Programs (IN5-1.002)." Neurology 80.Meeting Abstracts 1 (2013): IN5-1.

[5] Jing, Chen, et al. "Model for Physical Education Evaluation in University with Intuitionistic Fuzzy Information." Journal of Convergence Information Technology 7.7 (2012).

[6] Yan-Xia, Li, Li Lin, and Wang Qiang. "Research and Development of the Integrated Management System of the College Sports Based on the Network." Intelligent Systems Design and Engineering Applications, 2013 Fourth International Conference on. IEEE, 2013.

[7] Rai, Vaibhav. "A differentiation study on university players in relation to general motor ability." International journal of research pedagogy and technology in education and movement sciences 1.3 (2013): 23-29.

[8] Khanifar, Hossein, et al. "Evaluation of Tarbiat Modares University brand based on University Brand Ecosystem Models." International Journal of Academic Research in Business and Social Sciences 3.7 (2013): 628-642. 